\title{
Avaliação da suplementação com caseína sobre o periodonto e osso mandibular de ratos alimentados com dieta padrão e dieta de cafeteria
}

\author{
Evaluation of casein supplementation on periodontal and mandibular bone of rats fed standard diet \\ and cafeteria diet
}

Evaluación de la suplementación con caseína en periodonto y hueso mandibular de ratas alimentadas con una dieta estándar y una dieta de cafetería

\section{Resumo}

Objetivo: Avaliar o efeito da suplementação com caseína sobre o periodonto e osso mandibular de ratos alimentados com dieta padrão e dieta de cafeteria. Metodologia: 24 ratos Wistar foram divididos em quatro grupos experimentais: dieta normal (DN), dieta normal com caseína (DNC), dieta de cafeteria (DC) e dieta de cafeteria com caseína (DCC). Os grupos DNC e DCC receberam $2 \mathrm{~mL}$ de caseína micelar do $60^{\circ}$ ao $90^{\circ}$ dia. Aos 90 dias, os animais foram ortoeutanasiados e os materiais foram coletados para análise. Resultados: Os animais dos grupos DC e DCC apresentaram maior índice de adiposidade comparados a DN e DNC $(p<0001)$. O grupo DCC teve dosagem de colesterol HDL significativamente menor que DN $(\mathrm{p}<0,0092)$. Na análise radiográfica da hemimandíbula dos animais, não foi observada diferença em relação à densidade de pixels, entretanto, houve diferença no tamanho da porção anterior mandibular entre DCC e DNC $(p<0,0196)$ e DCC e DN $(p<0,0039)$. Histologicamente, observou-se redução de vasos sanguíneos, tanto em osso alveolar $(p=0,0033)$, osso da furca $(p<0,0001)$ e ligamento periodontal $(p=0,0001)$ em DCC. Além disso, no osso alveolar houve diminuição de osteócitos no grupo DCC em relação à $\mathrm{DNC}(\mathrm{p}=0,0198)$. Conclusões: $\mathrm{O}$ aumento da adiposidade contribuiu para diminuição de vasos sanguíneos e osteócitos no tecido ósseo de ratos, apesar de não influenciar na inflamação. Esse efeito foi independente de caseína. Portanto, a suplementação com caseína em ratos submetidos a dieta de cafeteria não foi efetiva para diminuir o acúmulo de tecido adiposo, bem como não interferiu positivamente no metabolismo ósseo da hemimandíbula.

Palavras-chave: Dieta de cafeteria; Proteína láctea; Caseína; Reabsorção óssea alveolar; Periodonto. 


\begin{abstract}
Objective: To evaluate the effect of casein supplementation on the periodontium and mandibular bone of rats fed a standard diet and a cafeteria diet. Methodology: 24 Wistar rats were divided into four experimental groups: normal diet (DN), normal diet with casein (DNC), cafeteria diet (DC) and cafeteria diet with casein (DCC). The DNC and DCC groups received $2 \mathrm{~mL}$ of micellar casein from the 60th to the 90th day. At 90 days, the animals were orthouthanized and the materials were collected for analysis. Results: The animals in the DC and DCC groups showed a higher adiposity index compared to DN and DNC $(\mathrm{p}<0001)$. The DCC group had a significantly lower HDL cholesterol level than DN $(p<0.0092)$. In the radiographic analysis of the animals' hemimandibula, no difference was observed in relation to pixel density, however, there was a difference in the size of the anterior mandibular portion between DCC and DNC $(\mathrm{p}<0.0196)$ and DCC and DN $(\mathrm{p}<0.0039)$. Histologically, there was a reduction in blood vessels, both in alveolar bone $(p=0.0033)$, furcation bone $(p<0.0001)$ and periodontal ligament $(p=0.0001)$ in CHD. In addition, in the alveolar bone there was a decrease in osteocytes in the DCC group in relation to the CND ( $\mathrm{p}=$ 0.0198). Conclusions: The increase in adiposity contributed to the decrease of blood vessels and osteocytes in the bone tissue of rats, despite not influencing inflammation. This effect was independent of casein. Therefore, casein supplementation in rats submitted to a cafeteria diet was not effective in decreasing the accumulation of adipose tissue, as well as not positively interfering in the bone metabolism of the hemimandibula.
\end{abstract}

Keywords: Cafeteria diet; Dairy protein; Casein; Alveolar bone resorption; Periodontium.

\title{
Resumen
}

Objetivo: Evaluar el efecto de la suplementación con caseína en el periodonto y el hueso mandibular de ratas alimentadas con una dieta estándar y una dieta de cafetería. Metodología: Se dividieron 24 ratas Wistar en cuatro grupos experimentales: dieta normal (DN), dieta normal con caseína (DNC), dieta de cafetería (DC) y dieta de cafetería con caseína (DCC). Los grupos DNC y DCC recibieron $2 \mathrm{~mL}$ de caseína micelar desde el día 60 al 90 . A los 90 días, los animales se ortotanizaron y los materiales se recogieron para su análisis. Resultados: Los animales de los grupos DC y DCC mostraron un mayor índice de adiposidad en comparación con DN y DNC ( $p<0001)$. El grupo DCC tuvo un nivel de colesterol HDL significativamente menor que el DN $(p<0,0092)$. En el análisis radiográfico de la hemimandibula de los animales, no se observó diferencia en relación a la densidad de píxeles, sin embargo, sí hubo diferencia en el tamaño de porción mandibular entre DCC y DNC ( $\mathrm{p}<0.0196)$ y DCC y DN $(\mathrm{p}<0.0039)$. Histológicamente, hubo una reducción de los vasos sanguíneos, tanto en el hueso alveolar $(p=0,0033)$, hueso de furca $(\mathrm{p}<0,0001)$ como en el ligamento periodontal $(\mathrm{p}=0,0001)$ en la EC. Además, en el hueso alveolar hubo una disminución de los osteocitos en el grupo DCC en relación con la CND $(p=0,0198)$. Conclusiones: El aumento de la adiposidad contribuyó a la disminución de vasos sanguíneos y osteocitos en el tejido óseo de ratas, a pesar de no influir en la inflamación. Este efecto fue independiente de la caseína. Por lo tanto, la suplementación con caseína en ratas sometidas a una dieta de cafetería no fue eficaz para disminuir la acumulación de tejido adiposo, ni tampoco interfirió positivamente en el metabolismo óseo del hemimandibula.

Palabras clave: Cafetería dietética; Proteína láctea; Caseína; Reabsorción ósea alveolar; Periodonto.

\section{Introdução}

A obesidade é uma doença inflamatória crônica de longa duração e caráter progressivo. São muitos os fatores que levam o indivíduo a se tornar obeso, e a mais comum é a ingesta alimentar excessiva, com alimentos hipercalóricos e ultraprocessados. Se esse comportamento é contínuo, forma-se cada vez mais tecido adiposo no organismo (Tappia \& Defried, 2020). A obesidade é um problema de saúde pública a nível mundial atualmente, já que é precursora de diversas outras comorbidades, como doenças cardiovasculares, endocrinológicas e osteo metabólicas (Schetz et al., 2019; Afobali et al., 2020; So \& Yadav, 2020). Embora a relação entre a obesidade e o metabolismo ósseo ainda não seja totalmente elucidada, nas últimas décadas estudos têm demonstrado relação entre obesidade, osteopenia e osteoporose (Greco et al., 2010; Gkastaris et al., 2020).

Hipotetizava-se que a obesidade teria um efeito protetor ósseo, devido à maior pressão sobre essa estrutura, além da proteção física proporcionada pelo tecido adiposo em possíveis quedas (Felson et al., 1993; Cao, 2011; Mirzababaei et al., 2017; Walsh \& Vilaça, 2017). Porém, essas premissas se mostraram cada vez mais contraditórias ao longo do tempo, já que as observações clínicas e diversos estudos têm demonstrado que pacientes obesos frequentemente apresentam osteopenia/osteoporose e risco aumentado de fraturas em alguns sítios específicos, como tornozelo e úmero (Compston et al., 2011; Compston et al., 2014; Gkastaris et al., 2020). Sawin e colaboradores (2016) verificaram que uma alimentação hiper lipídica em camundongos fêmeas aumenta a mineralização do osso, mas afeta negativamente sua qualidade, resultando em 
ossos fracos e quebradiços, aumentando o risco de fraturas.

Os mecanismos propostos para explicar os efeitos deletérios da obesidade no tecido ósseo são: a) quanto maior a proliferação do tecido adiposo, menos osteoblastos se formam na medula óssea, uma vez que eles são oriundos de uma célulatronco mesenquimal multipotente comum; b) devido ao fato do maior número de citocinas pró-inflamatórias circulantes, pode haver a modulação das vias ligadas ao remodelamento ósseo, gerando maior reabsorção pela maior ativação osteoclástica; c) mutação do gene da proteína da obesidade e de massa de gordura associada - FTO (alpha-ketoglutarate-dependente dioxigenase), levando à ganho de peso e fragilidade óssea; e d) aumento do metabolismo e senescência acelerada em célulastronco estromais (Benayahu, Wiesenfeld \& Sapir-Koren, 2019; Rauch et al., 2019; Zhou, Li \& Pathak, 2019; Proietto, 2020.

$\mathrm{O}$ tecido adiposo contribui para integridade esquelética possivelmente devido a secreção de várias adipocinas, as quais influenciam a remodelação óssea. Da mesma forma, o tecido ósseo também desempenha função regulatória no peso corporal e homeostase da glicose através da osteocalcina e osteopontina. Embora os mecanismos ainda não estejam totalmente elucidados, o tecido adiposo e o esquelético possuem um eixo de regulação entre si (Gomez-Ambrosi et al., 2008; Kim et al., 2017; Gkastaris et al., 2020).

É bem estabelecido que doenças sistêmicas têm impacto em sítios específicos do organismo, como, por exemplo, na cavidade bucal. Na obesidade já instalada, síndrome metabólica, diabetes mellitus, entre outras, ocorre o acometimento ou agravamento de doenças bucais pré-existentes, com aumento da reabsorção óssea alveolar, diminuição da densidade mineral óssea e prejuízo na estrutura óssea trabecular. Essas alterações impactam diretamente a remodelação dos ossos (Ramos-Junior et al. 2017; Wong et al., 2018).

O consumo de suplementos alimentares para fins de emagrecimento movimenta bilhões de dólares ao ano (Nahin et al., 2009). Dentre estes suplementos, frações proteicas do leite, como whey protein e a caseína são utilizadas, muitas vezes de forma empírica. Especificamente a respeito da caseína, a premissa é que, devido à sua lenta digestão e absorção, haveria aumento da saciedade por períodos prolongados, e assim, menor ganho ponderal (Kouw et al., 2017). Entretanto, há divergências na literatura disponível acerca dos efeitos da caseína na obesidade. Lillefosse e colaboradores (2013) demonstrou que a caseína hidrolisada reduziu a obesidade induzida por dieta em ratos, e esses resultados são compatíveis com outros estudos (Schoemaker et al., 2017). Chia e colaboradores (2018), entretanto, observaram que a caseína fração A1 pode modificar o metabolismo da glicose e induzir o acometimento da diabetes tipo 1, às vezes o efeito aparecendo em gerações futuras.

A respeito da influência destes suplementos lácteos no metabolismo ósseo, Fried e colaboradores (2012) conduziram um estudo com ratos no qual observaram que a ingestão de leite desnatado em pó enriquecido com 2,4\% de cálcio, por oito semanas, melhorou a estrutura óssea trabecular, em relação aos ratos que receberam caseína ou whey protein. Resultados semelhantes haviam sido encontrados por Eller e Reimer (2010), nos mesmos parâmetros. Entretanto, um recente estudo concluiu que ratos alimentados com leite de soja tiveram melhor qualidade óssea, em relação a ratos que ingeriram caseína (Duque et al., 2020).

Levando-se em consideração a escassez de estudos sobre o tema os resultados contraditórios apresentados, o objetivo deste estudo foi avaliar o efeito da suplementação com caseína sobre os parâmetros somatométricos e valores de pixel da hemimandíbulas de ratos alimentados com dieta padrão e dieta de cafeteria. Além disso, este estudo buscou avaliar os possíveis efeitos desta suplementação na histologia óssea, por meio da análise do ligamento periodontal, osso alveolar e tecido ósseo presente na região de furca.Use o parágrafo como modelo. 


\section{Metodologia}

\section{Animais e Comitê de ética}

Para este estudo foram utilizados 24 ratos, 12 machos e 12 fêmeas, da linhagem Wistar (Rattus norvergicus), com 21 dias de vida. Os animais foram mantidos no Núcleo Avançado de Estudos da Vida (NAEVI-UEPG) em caixas para roedores, com cama de maravalha, em condições de temperatura controlada de $21 \pm 2^{\circ} \mathrm{C}$, com luminosidade em ciclo claro/escuro de 12 horas, alimentados com ração comercial balanceada e água potável ad libitum.

Esta pesquisa foi aprovada pelo Comitê de Ética em Experimentação Animal (CEUA) da UEPG, processo $\mathrm{n}^{\circ}$ 7707/2018. Foram utilizadas todas as medidas para manter o bem-estar animal e minimizar dor e desconforto dos animais, de acordo com a Lei $n^{\circ} 11.794$, de 08 de outubro de 2008; e Decreto $n^{\circ} 6.899$ de 15 de julho de 2009.

\section{Dieta padrão, dieta de cafeteria e desenho experimental}

Os animais do grupo controle foram alimentados ad libitum com água potável e dieta padrão NUVILAB-CR1 (Nuvital - Colombo/PR, Brasil). Aos 30 dias de vida, os animais foram divididos em dois grupos experimentais: grupo dieta normal (6 machos e 6 fêmeas) e grupo dieta de cafeteria (6 machos e 6 fêmeas). Então, a partir do $60^{\circ}$ dia, os grupos foram subdivididos, resultando em quatro grupos: grupo dieta normal sem suplementação de caseína (DN); grupo dieta normal com suplementação de caseína (DNC); grupo dieta de cafeteria sem suplementação de caseína (DC); grupo dieta de cafeteria com suplementação de caseína (DCC).

A dieta de cafeteria foi ofertada ad libitum diariamente ao grupo DC e DCC, a partir do $30^{\circ}$ dia de vida. Os itens que compõem a dieta foram agrupados em três combinações distintas ofertadas alternadamente (A, B, C - tabela 1). A dieta A era oferecida às segundas-feiras, a dieta $\mathrm{B}$ às quartas-feiras e a dieta $\mathrm{C}$ às sextas-feiras, compostas por alimentos frescos, refrigerante de cola, ração padrão e água. O cardápio de alimentos hipercalóricos para compor este modelo de dieta de cafeteria tem base nos trabalhos de Didek e colaboradores (2019).

Tabela 1 - Cardápio oferecido aos ratos pertencentes aos grupos “dieta de cafeteria” (DNC e DCC).

\begin{tabular}{|c|c|c|c|c|c|c|}
\hline \multirow{2}{*}{ ALIMENTO } & \multicolumn{2}{|c|}{ CARDÁPIO A } & \multirow[b]{2}{*}{ Carboidrato (g) } & \multirow[b]{2}{*}{ Proteína (g) } & \multirow[b]{2}{*}{ Lipídios (g) } & \multirow[b]{2}{*}{ Sódio (mg) } \\
\hline & Qtd (g) & $\mathrm{Kcal} / \mathrm{g}$ & & & & \\
\hline Ração padrão & 1 & 2,95 & 0,55 & 0,22 & 0,04 & 0,00 \\
\hline Salgadinho sabor queijo & 1 & 3,92 & 0,72 & 0,08 & 0,09 & 12,3 \\
\hline Bolacha wafer de chocolate & 1 & 5,56 & 0,63 & 0,03 & 0,51 & 0,76 \\
\hline \multirow[t]{2}{*}{ Refrigerante de cola } & 1 & 0,42 & 0,11 & 0,00 & 0,00 & 0,05 \\
\hline & \multicolumn{2}{|c|}{ CARDÁPIO B } & & & & \\
\hline Ração padrão & 1 & 2,95 & 0,55 & 0,22 & 0,04 & 0,00 \\
\hline Marshmallow & 1 & 3,35 & 0,82 & 0,04 & 0,00 & 0,25 \\
\hline Apresuntado & 1 & 1,85 & 0,07 & 0,13 & 0,16 & 11,7 \\
\hline \multirow[t]{2}{*}{ Refrigerante de cola } & 1 & 0,42 & 0,11 & 0,00 & 0,00 & 0,05 \\
\hline & \multicolumn{2}{|c|}{ CARDÁPIO C } & & & & \\
\hline Ração padrão & 1 & 2,95 & 0,55 & 0,22 & 0,04 & 0,00 \\
\hline Salgadinho sabor bacon & 1 & 5,08 & 0,521 & 0,08 & 0,29 & 6,40 \\
\hline Bolacha maria & 1 & 4,30 & 0,73 & 0,07 & 0,12 & 4,33 \\
\hline Refrigerante & 1 & 0,42 & 0,11 & 0,00 & 0,00 & 0,05 \\
\hline
\end{tabular}


Aos 60 dias de vida, os grupos DNC e DCC iniciaram a suplementação por 30 dias com caseína micelar pelo método de gavagem. Foi escolhido esse período de suplementação pois a partir do $60^{\circ}$ dia de vida os animais já são considerados adultos jovens, e não foi objetivo do presente estudo verificar a influência da suplementação. de caseína na infância. A caseína utilizada foi Gold Standart 100\% Casein da marca comercial Optimum Nutrition. A dose administrada, via gavagem, foi calculada levando-se em consideração a dose usualmente utilizada por humanos (30 a 35 gramas/dia), proporcionalmente extrapolada conforme o metabolismo dos animais. Assim, foram administrados 0,3 gramas de caseína em $2 \mathrm{~mL}$ de água, para cada animal, uma vez ao dia, no período da manhã, sempre no mesmo horário. Os animais que não receberam caseína, receberam $2 \mathrm{~mL}$ de soro fisiológico via gavagem (controle negativo). A escolha do período da manhã foi feita considerando o hábito noturno dos roedores, já que a caseína é uma proteína de absorção lenta e deve ser administrada preferencialmente antes do sono.

Então, aos 90 dias de vida, os animais foram pesados e submetidos à ortoeutanásia por decapitação e remoção de materiais para análises post-mortem (gorduras, sangue e hemimandíbulas). As gorduras mesentérica, perigonadal e retroperitoneal foram removidas, lavadas com solução salina tamponada com fosfato (PBS) e pesadas em balança digital de precisão analítica (Quimis, modelo Q-500L210C).

\section{Avaliação da obesidade}

$\mathrm{O}$ índice de adiposidade (IA) post-mortem foi calculado utilizando a fórmula: IA = [gordura corporal/peso corporal] $\mathrm{x}$ 100. A gordura corporal $(\mathrm{g})$ foi calculada pela soma dos seguintes constituintes do tecido adiposo: gordura perigonadal + gordura retroperitoneal + gordura mesentérica (Jacobsen et al., 2017).

O sangue coletado $(2 \mathrm{~mL})$ foi destinado a exames laboratoriais. Após a coleta do sangue total em tubo gel ativador de cóagulo (Vacuplast - Cotia/SP) foi centrifugado a 3.000 RPM por 10 minutos em centrífuga Celm LS-3 plus, para as seguintes dosagens: a) glicemia b) triglicerídeos d) colesterol total, e colesterol HDL, transaminases (TGO/TGP). Estes exames foram realizados pelo método enzimático colorimétrico no analisador bioquímico CT300i Wiener. As dosagens foram realizadas com reagentes da marca (Wiener Lab, Rosário, Argentina).

Foi medido o comprimento naso-anal $(\mathrm{cm})$ e peso do animal $(\mathrm{g})$ para cálculo do índice de Lee (valor preditivo de obesidade em roedores) (Bernardis \& Patterson, 1968), de acordo com a equação: Índice de Lee $=\{\sqrt[3]{[}[$ Massa corporal $(\mathrm{g})] /[$ Comprimento nasoanal $(\mathrm{cm})]\} \times 1000$.

\section{Análises radiográficas}

As hemimandíbulas foram dissecadas e fixadas em formol a $10 \%$ durante 24 horas, expostas durante 12 horas a solução de peróxido de hidrogênio 3\%, seguido pela remoção mecânica dos tecidos moles remanescentes. As mandíbulas foram submetidas à análise radiográfica por meio de um aparelho digital (Sensor para radiografia digital, Micro Imagem, EVO/FIT, Indaiatuba, Brasil). Para a análise radiográfica, cada hemimandíbula foi posicionada paralelamente sobre o filme radiográfico com uma distância focal de $10 \mathrm{~cm}$ do cilindro do equipamento radiográfico. O tempo de exposição foi definido em 0,50 segundos. As medidas somatométricas foram analisadas por meio do programa ImageJ (Wayne Rasband do Research Services Branch, Bethesda, Estados Unidos), sendo elas: altura anterior (traçado 1), altura posterior (traçado 2), comprimento anterior (traçado 3), comprimento posterior (traçado 4) ângulo gonial (de 5-7/ plano mandibular) e área líquida (área da mandíbula menos a região de sulco). A análise dos valores de pixels, referente à escala de cinza, foi avaliada em 10 pontos distribuídos, nomeados de P1 a P10, em duas regiões da hemimandíbula (Dalmolin et al., 2018; Brin, Michaeli \& Steigman, 1990). Tanto as medidas somatométricas quanto os pontos de análise de pixels estão ilustrados na Figura 1. 
Figura 1 - Medidas somatomátricas realizadas na hemimandíbula (em amarelo). 1) Altura anterior; 2) Altura posterior; 1-3) Comprimento anterior; 3-5, 3-6, 3-7, 3-8, 3-9) Comprimento posterior; 5-7) Ângulo Ganíaco; 6) Área líquida. Pontos onde a escala de cinza foi analisada (em azul) (P1-P10).

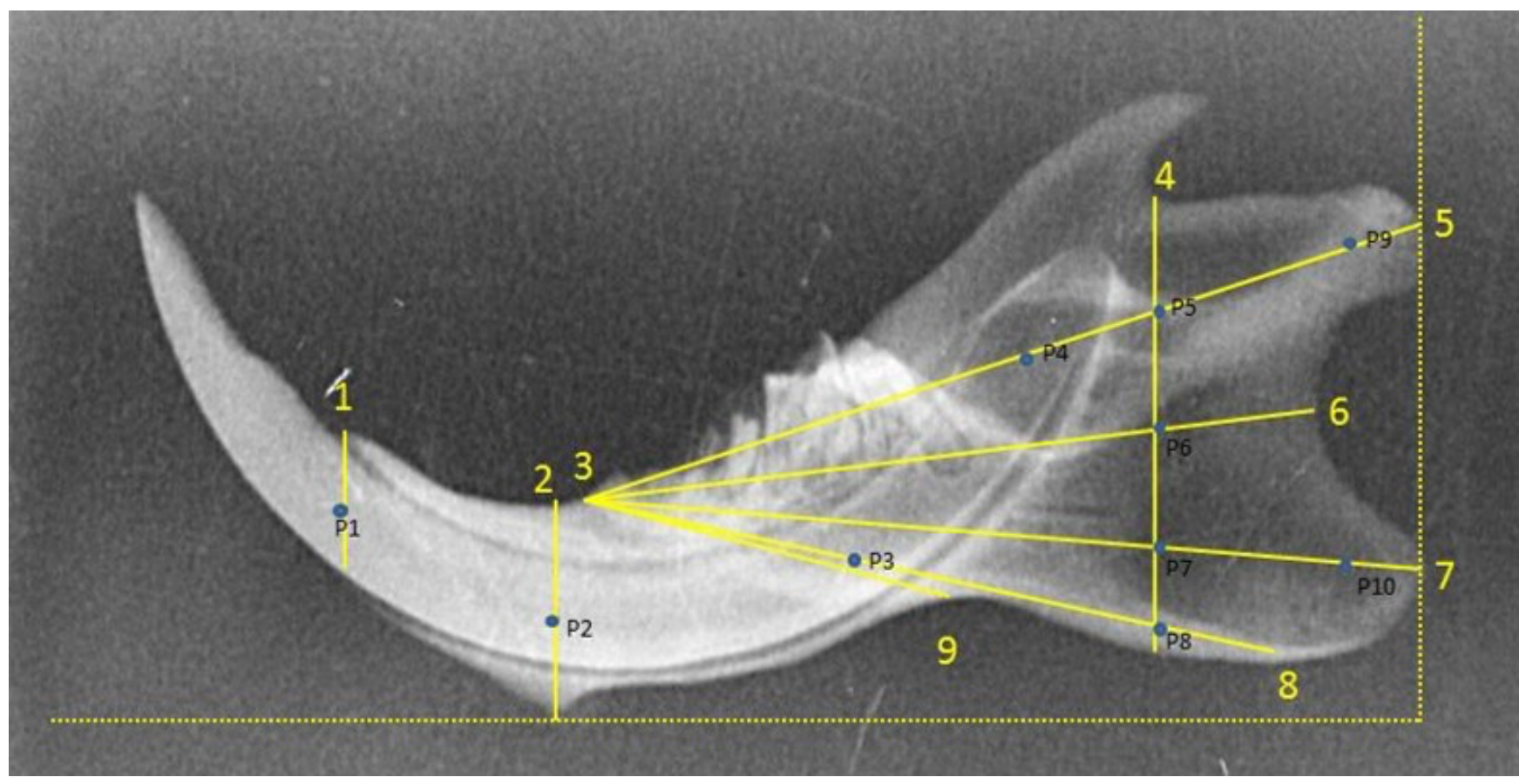

Fonte: Autores.

\section{Análises histológicas}

Para as análises histológicas, foi feita a dissecção e remoção mecânica dos tecidos moles das hemimandíbulas. Em seguida, foram fixadas em formol a 10\% durante 24 horas, e descalcificadas em ácido etilenodiamino tetraacético (EDTA) a 9\%, sob agitação constante até a completa desmineralização. O material foi processado em um histotécnico de sistema semifechado (Leica Microsystems, Buffalo Grove, Estados Unidos) onde passou pelas etapas de desidratação, diafanização e impregnação de parafina. As amostras foram então posicionadas num plano coronal e incluídas em blocos de parafina. Foram realizados cortes sagitais de cinco micrômetros, seguido pela desparafinização, hidratação, coloração em hematoxilina e eosina (HE), desidratação e montagem. Em cada lâmina, foram fotografadas cerca de 23 áreas com ampliação de 200x em três regiões distintas: osso alveolar, ligamento e osso da furca por meio da plataforma Olympus CellSens (CellSens Software 1.6, Tóquio, Japão). Para análise do ligamento periodontal, foram visualizados 13 campos, contemplando todo espaço ocupado pelo ligamento periodontal - iniciando imediatamente acima da crista óssea do osso alveolar, seguindo até a proximidade com o ápice radicular. Para análise da região do osso alveolar, foram escolhidos 5 campos sequenciais a partir da crista óssea, e para a região do osso da furca, também foram selecionados 5 campos. As imagens obtidas foram analisadas com o auxílio do programa ImageJ (National Institute of Mental Health-Bethesda, Maryland, Estados Unidos) visando a identificação e quantificação das estruturas. Utilizou-se o plugin "Grid" que seccionada as imagens em 80 pontos equidistantes e as contagens foram realizadas com auxílio do plugin "Point tool", onde cada estrutura era marcada e contada exatamente nestes pontos de intersecções para todos os campos. Os elementos contabilizados em cada região estão descritos na Tabela 2. Para obtenção dos percentuais, o total das contagens desses 80 pontos foi transformado em $100 \%$, e, de posse dessas informações para cada campo e região, os dados foram plotados em uma planilha (Windows Excel, Microsoft, Redmond, WA, Estados Unidos) para análise estatística. 
Tabela 2 - Regiões das hemimandíbulas e os respectivos elementos histológicos avaliados.

\begin{tabular}{ccc}
\hline $\begin{array}{c}\text { REGIÃO DAS } \\
\text { HEMIMANDÍBULAS }\end{array}$ & $\begin{array}{c}\text { CAMPOS } \\
\text { (AMPLIAÇÃO 200X) }\end{array}$ & CARACTERÍSTICAS DA REGIÃO \\
Ligamento periodontal & 13 campos & $\begin{array}{c}\text { Fibras colágenas, fibroblastos, células } \\
\text { inflamatórias, vasos sanguíneos }\end{array}$ \\
Osso alveolar & 5 campos & $\begin{array}{c}\text { Matriz óssea, osteócitos, vasos sanguíneos, células } \\
\text { inflamatórias }\end{array}$ \\
Osso da furca & 5 campos & $\begin{array}{c}\text { Matriz óssea, osteócitos, vasos sanguíneos, medula } \\
\text { óssea e células inflamatórias }\end{array}$ \\
\hline
\end{tabular}

Fonte: Autores.

\section{Análise estatística}

A partir dos dados obtidos, realizou-se um cálculo de poder amostral a posteriori e, para a expectativa de sucesso de $20 \%$, o poder da amostra utilizada no presente estudo foi de 50\%. A normalidade dos dados foi verificada pelo teste de Shapiro-Wilk. Os dados que apresentaram distribuição normal foram submetidos aos testes paramétricos (One-way ANOVA e teste de Tukey). Os dados que não apresentaram distribuição normal foram submetidos a testes não paramétricos (One-way ANOVA e teste de Kruskal-Wallis). Todas as análises foram realizadas no software Graphpad Prisma Versão 8.0.1, com um nível de confiância 95\%, os dados apresentados são a média mais ou menos o desvio padrão médio. Foram considerados valores estatisticamente significativos $\mathrm{p}<0,05$.

\section{Resultados}

Não houve diferença estatística no peso e no índice de Lee dos quatro grupos experimentais, entretanto houve diferença significativa no índice de adiposidade entre os grupos DN e DC, DN e DCC, DNC e DC e DNC e DCC (p<0,0001), com aumento expressivo de tecido adiposo nos grupos tratados com dieta de cafeteria. A intervenção com caseína não resultou em diferença estatisticamente significativa (DN em relação a DNC, e DC em relação a DCC). A Figura 2 mostra os gráficos dos pesos, índice de adiposidade e índice de Lee dos quatro grupos experimentais analisados.

Figura 2 - Avaliação do peso (A), adiposidade (B) e índice de Lee (C) nos grupos DN, DNC, DC e DCC. Aumento na adiposidade DN e DC ( $p=0,0001)$, DN e DCC ( $p=0,0001)$, DNC e DC ( $p=0,0001)$ e DNC e DCC ( $p=0,0001)$.
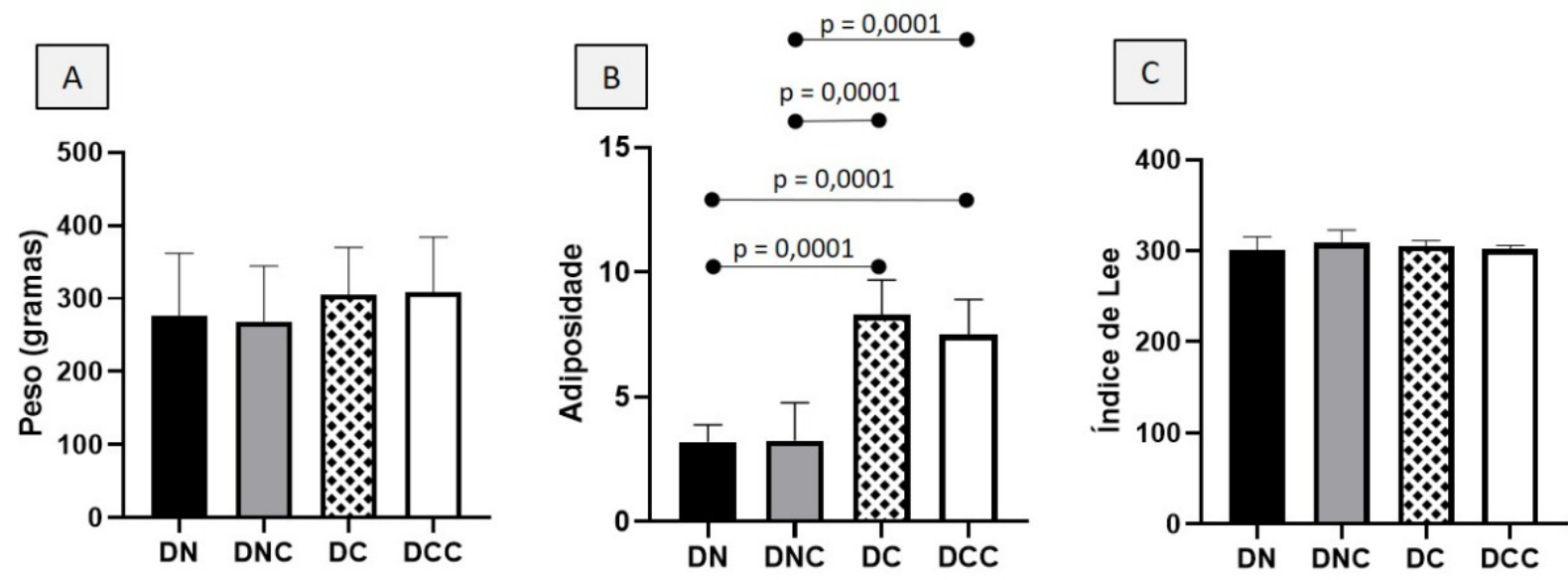

Fonte: Autores. 
Não houve diferença estatística entre os grupos nos testes bioquímicos realizados (colesterol total, triglicerídeos, glicemia, transaminase oxaloacética, transaminase pirúvica), exceto para o colesterol HDL, que apresentou diferença significativa entre os grupos DN e DCC ( $<<0,0092)$, com redução do valor para o grupo da dieta de cafeteria suplementado com caseína. As análises sorológicas realizadas estão esquematizadas na Figura 3.

Figura 3 - Análises sorológicas. A) colesterol total (mg/dL); B) colesterol HDL (mg/dL) - diferença significativa DN e DCC $(\mathrm{p}=0,0092) ; \mathrm{C})$ triglicerídeos $(\mathrm{mg} / \mathrm{dL}) ; \mathrm{D})$ glicemia $(\mathrm{mg} / \mathrm{dL}) ; \mathrm{E})$ transaminase oxaloacética - TGO $(\mathrm{mg} / \mathrm{dL}) ; \mathrm{F})$ transaminase pirúvica - TGP (mg/dL).


Fonte: Autores.

Para as análises das medidas somatométricas mandibulares, verificou-se redução da altura anterior (traçado 1) nos grupos tratados com dieta de cafeteria, tendo diferença estatística entre os grupos DCC com DNC ( $<<0,0196)$ e DCC com DN $(p<0,0039)$ (Figura 4). Ainda sobre as análises radiográficas, após aplicação dos testes estatísticos, verificou-se que não houve diferença significativa para nenhum dos dez pontos onde mensurou-se a densidade de pixels nas radiografias (Figura 5). 
Figura 4 - Medidas somatométricas da hemimandíbula de ratos tratados com dieta normal e dieta de cafetaria, suplementados ou não com caseína. A) medida 1 (altura anterior) - diferença significativa DN e DCC ( $p=0,0039)$ e DNC e DCC ( $p=0,0196)$; B) medida 2 (altura posterior); C) medida 3 (comprimento anterior); D) medida 4 (comprimento posterior); E) medida 5 (ângulo goníaco); F) medida 6 (área líquida da mandíbula).
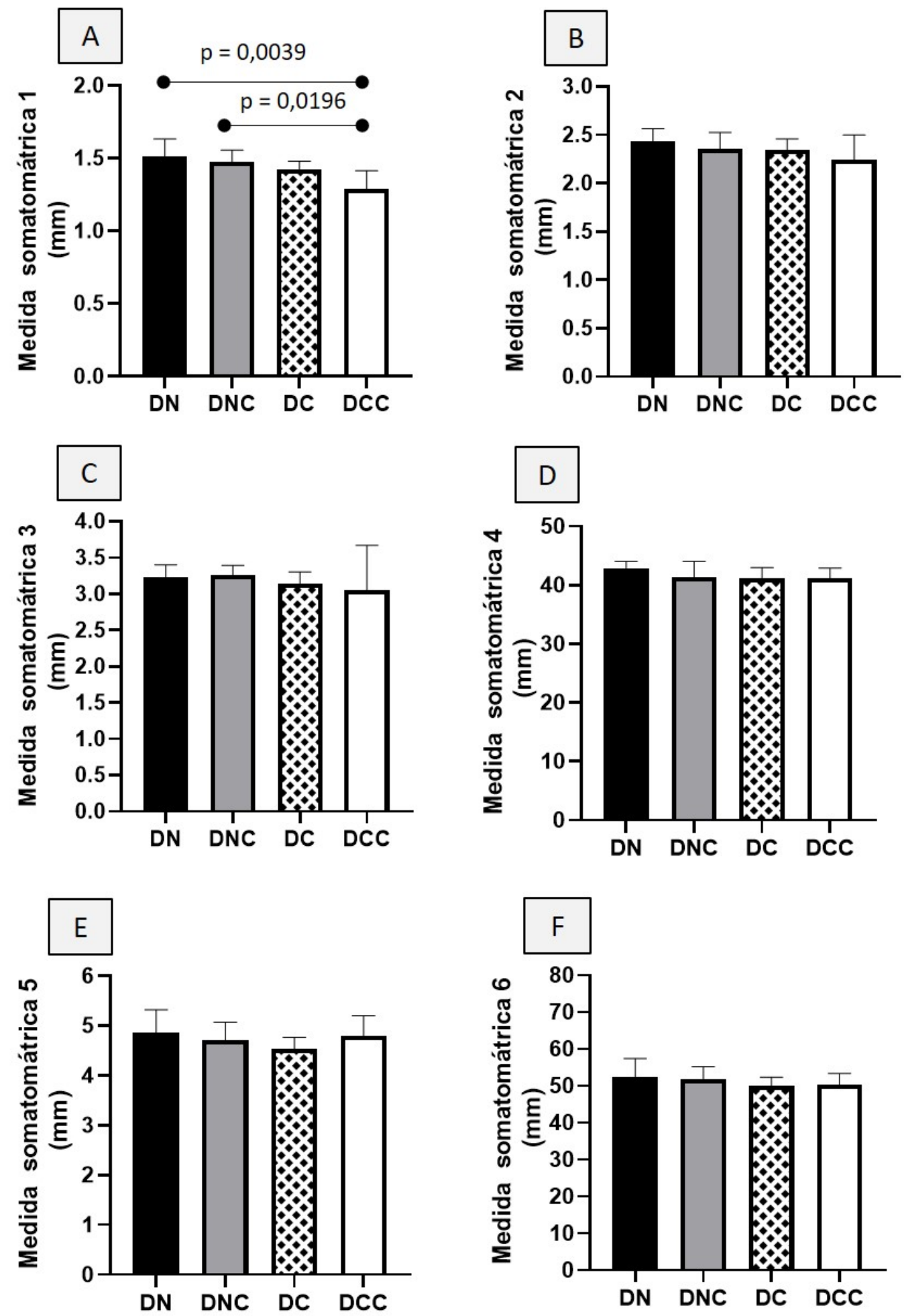

Fonte: Autores. 
Figura 5 - Avaliação da variação na escala de cinza por meio de valores de pixel em 10 pontos da hemimandíbula. A) ponto 1; B) ponto 2 ; C) ponto 3 ; D) ponto 4 ; E) ponto 5 ; F) ponto 6 ; G) ponto 7 ; H) ponto 8 ; I) ponto 9; J) ponto 10.
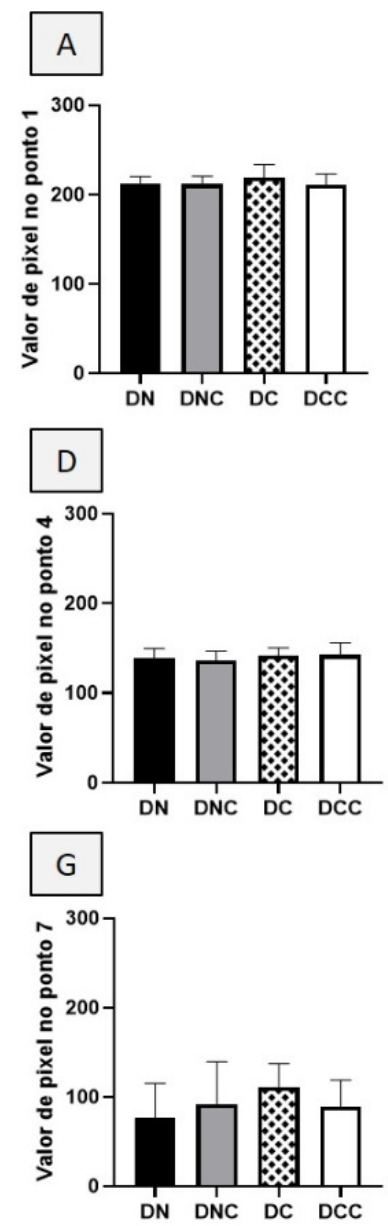
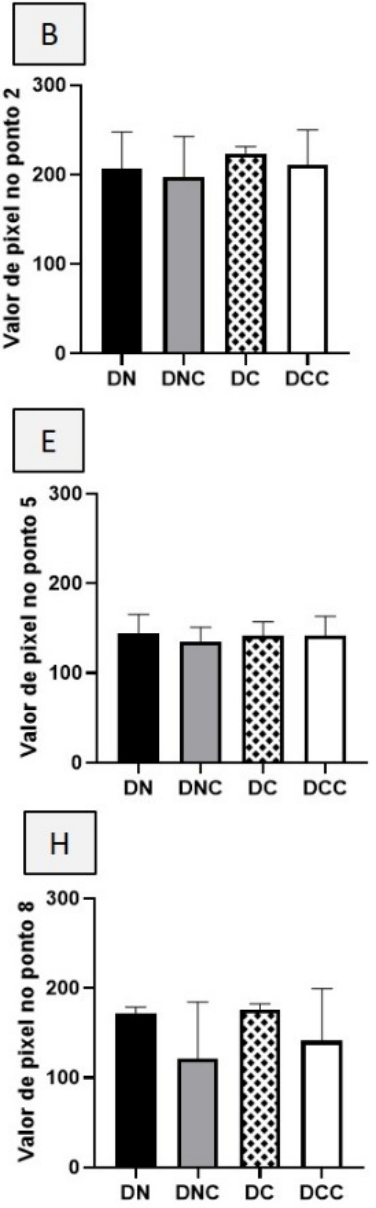


Fonte: Autores.

Nas análises histológicas realizadas, resultou em diferença significativa no osso alveolar: matriz óssea aumentada em $\mathrm{DCC}$, em relação à $\mathrm{DN}(\mathrm{p}=0,0456)$ e $\mathrm{DCC}$ em relação a $\mathrm{DNC}(\mathrm{p}=0,0029)$; diminuição de osteócitos em $\mathrm{DCC}$, em relação à DNC ( $p=0,0198)$; diminuição dos vasos sanguíneos, de DN para DCC ( $p=0,0033)$ e DN para DC (p=0,0003) (Figura 6). No osso da furca, observou-se aumento significativo da matriz óssea de DN para DC (p=0,0049) e DNC e DC (p=0,0047); e diminuição dos vasos sanguíneos, de DN para DC $(\mathrm{p}=<0,0001)$, DN para DCC $(\mathrm{p}=<0,0001)$, DNC para DC ( $\mathrm{p}=0,0001)$ e DNC para DCC ( $\mathrm{p}=0,0002)$ (Figura 7). No ligamento periodontal, observou-se apenas diferença estatística na quantidade de vasos sanguíneos, que se mostraram aumentados em DN, em relação a DCC ( $p=0,0001)$ e DN e DNC $(p=0,0062)($ Figura 8). 
Figura 6 - Densidade de volume no osso alveolar. A) matriz óssea (\%) - diferença significativa DN e DCC (p=0,0456) e DNC e DCC ( $\mathrm{p}=0,0029)$; B) osteócitos (\%) - diferença significativa DNC e DCC ( $\mathrm{p}=0,0198)$; C) vasos sanguíneos (\%) - diferença significativa DN e DCC ( $\mathrm{p}=0,0033)$ e DN e DC ( $\mathrm{p}=0,0003)$; $\mathrm{D})$ medula óssea.
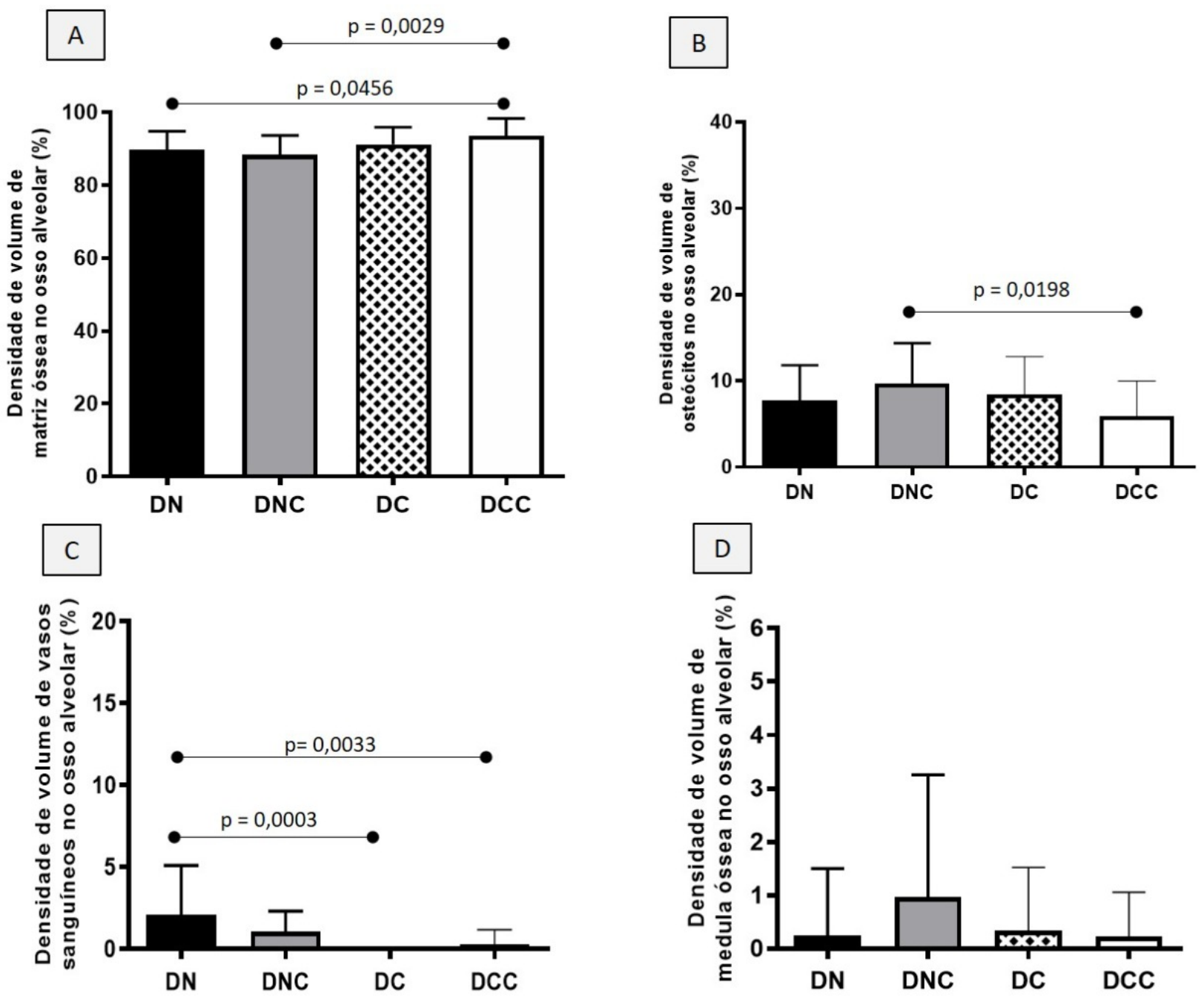

Fonte: Autores. 
Figura 7 - Densidade de volume no osso da furca. A) matriz óssea (\%) - diferença significativa DN e DC (p=0,0049) e DNC e DC ( $(\mathrm{p}=0,0047) ; \mathrm{B})$ osteócitos $(\%)$; $)$ vasos sanguíneos $(\%)$ - diferença significativa DN e DC (p=<0,0001), DN e DCC $(\mathrm{p}=<0,0001)$, DNC e DC ( $\mathrm{p}=0,0001)$ e DNC e DCC ( $\mathrm{p}=0,0002)$; e D) células inflamatórias.
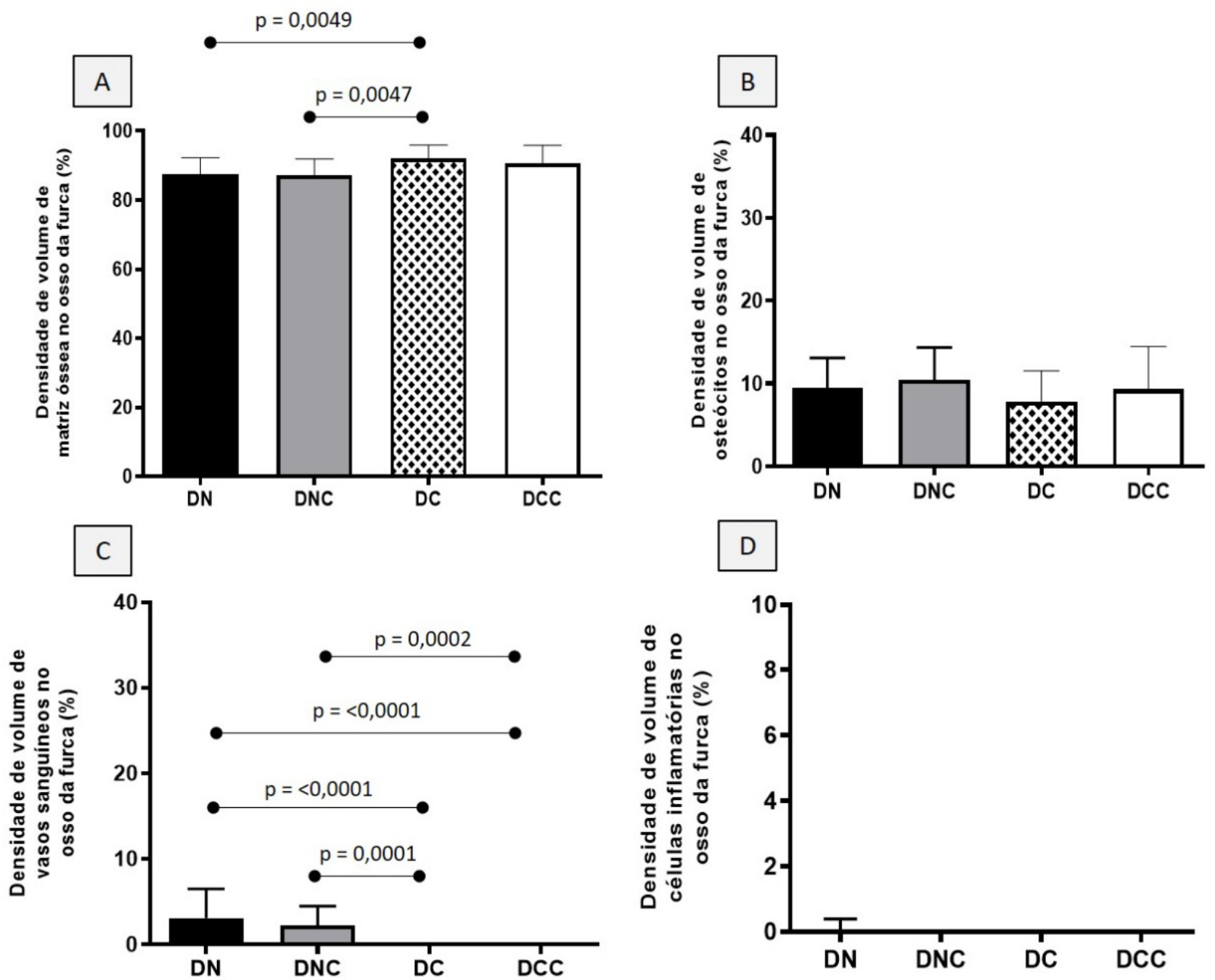

Fonte: Autores. 
Figura 8 - Densidade de volume no ligamento periodontal. A) fibras colágenas (\%); B) fibroblastos (\%); C) células inflamatórias (\%); D) vasos sanguíneos - diferença significativa DN e DCC ( $p=0,0001)$ e DN e DNC ( $\mathrm{p}=0,0062)$.

\section{A}

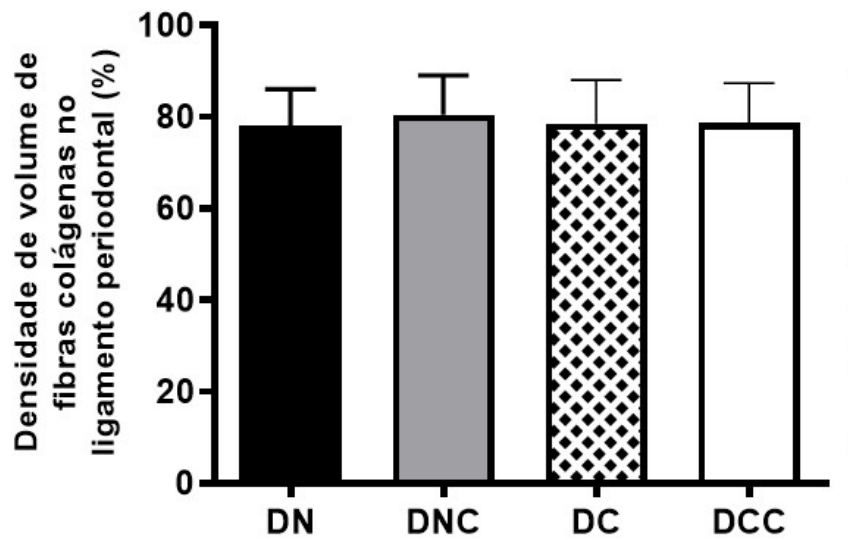

C



B

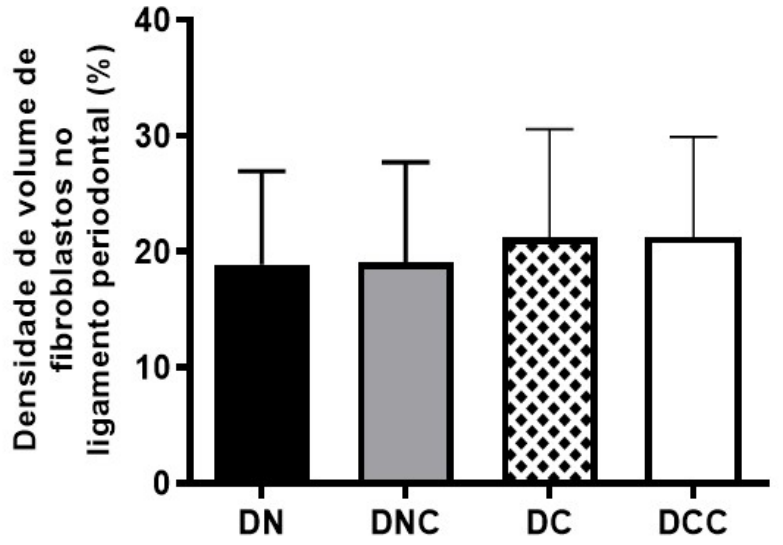

D



Fonte: Autores.

\section{Discussão}

Embora seja uma doença prevenível com a adoção de bons hábitos de vida, como alimentação natural e prática de atividade física, a obesidade mundial triplicou desde 1975. De acordo com Organização Mundial de Saúde (OMS, 2018), tratase de uma pandemia de grande relevância na saúde pública, por estar correlacionada com doenças com altas taxas de morbimortalidade. Neste contexto, a suplementação com caseína vem sendo utilizada, empiricamente, para minimizar o ganho de peso devido ao aumento da saciedade (Hall et al., 2003), já que a ingesta energética excessiva é o fator mais relevante na instalação da obesidade.

Os efeitos da caseína no metabolismo ósseo em animais induzidos à obesidade são parcialmente conhecidos, e não há homogeneidade nos resultados (Fried et al., 2012; Eller \& Reimer, 2018; Duque et al., 2020). Assim, o objetivo deste estudo foi avaliar o efeito da suplementação com caseína sobre os parâmetros somatométricos e valores de pixel da hemimandíbulas de ratos alimentados com dieta padrão e dieta de cafeteria. Avaliou-se também os possíveis efeitos desta suplementação no ligamento periodontal, no osso alveolar e no tecido ósseo presente na região de furca. 
A pesquisa na área de obesidade envolve o uso de modelos animais para facilitar o entendimento de processos biológicos envolvidos nas doenças, e o potencial das terapias novas e já existentes. Os roedores compartilham grande similaridade e equivalência genômica com humanos (Coltri et al., 2017). Nestes estudos, os modelos obesogênicos com oferta de dietas ricas em carboidratos e gorduras são simples e os que mais se assemelham à realidade da instalação da obesidade em humanos, sendo melhores do que a utilização de animais geneticamente modificados. Assim, são considerados melhor escolha para análise de estratégias terapêuticas (Barrett, Mercer \& Morgan, 2016). Particularmente a "dieta de cafeteria" condiz mais fidedignamente a situação humana, pois nestas os animais têm acesso a produtos contemporâneos (Marine-Casado et al., 2018).

Dos resultados obtidos neste estudo, não houve diferença significativa no peso e índice de Lee dos animais que receberam dieta normal, balanceada e própria para roedores, e os animais que receberam a dieta de cafeteria. Entretanto, houve aumento expressivo da adiposidade entre esses grupos. Já que a obesidade é uma doença de instalação gradual e progressiva, e o fato de os animais estarem expostos à alimentação obesogênica e ultraprocessada reproduz o contexto alimentar de grande parte da população, e por isso é um modelo experimental adequado para tentar reproduzir a realidade humana atual (MarineCasado et al., 2018).

Neste trabalho, utilizou-se análises radiográficas para verificar o metabolismo ósseo, tanto em relação às dimensões (somatometria) quanto à densidade (valores de pixels). Dos resultados obtidos, verificou-se que a porção anterior da mandíbula foi maior no grupo que recebeu dieta padrão, em relação ao grupo que recebeu dieta de cafeteria). Já que essa região mandibular é a mais utilizada pelos roedores no processo alimentar, levantou-se a hipótese de que a dureza da ração padrão poderia ter provocado uma maior reabsorção óssea. Conforme explica a Lei de Wolff, os ossos sofrem remodelação óssea conforme são utilizados. Essa relação entre remodelação óssea e tensão aplicada ao osso diz que um aumento na carga fará com que a estrutura interna esponjosa se fortaleça, assim como a diminuição do estresse aplicado no osso fará com que ele enfraqueça (Rowe, Koller \& Sharma, 2020).

Quando a radiografia é exibida em uma tela, é organizada por linhas e colunas de pixels. Cada pixel possui uma cor em uma escala de cinza, entre o preto e o branco. Essa variação nos tons de cinza pode ser relacionada com a densidade mineral do osso (Mundim et al., 2016). Nas análises de pixels do presente estudo, não houve diferença estatística entre os pontos analisados. A ausência de diferença nos valores de pixel sugere ausência de variação na densidade óssea, portanto. Contudo, a análise de pixel não é muito específica e, por este motivo, pode não se tratar da análise mais adequada neste contexto (Khojastepour et al., 2017).

A respeito das análises histológicas, a suplementação com caseína resultou em redução na vascularização do periodonto, tanto do osso alveolar, quanto do osso da furca, quanto do ligamento periodontal. Os resultados obtidos são contrários ao esperado, pois uma maior inflamação decorrente da obesidade geraria maior quantidade de citocinas inflamatórias circulantes, com maior vascularização. Estudo realizado por Messer e colaboradores (2019) demonstrou que ratos que receberam dieta rica em açúcar e caseína por 24 semanas tiveram resposta inflamatória em tecido periodontal sem qualquer intervenção mecânica. Outros estudos utilizaram dieta rica em açúcar combinada com caseína para induzir periodontite em roedores (Messer et al., 2017). Possivelmente, o tempo de exposição à dieta obesogênica do presente estudo foi menor do que o necessário, já que a inflamação advinda da obesidade é baixa e os animais eram adultos jovens, necessitando mais tempo para instalação da doença. Outra hipótese é que a caseína foi administrada via gavagem, sendo direcionada diretamente no estômago do animal, diferente dos pallets utilizados nos estudos de Messer de 2017 e 2019. Isso poderia ter minimizado a inflamação gengival nos animais do presente estudo.

A respeito da utilização da caseína em forma de suplemento como uma estratégia para minimizar os impactos negativos da obesidade no organismo, Healy e col. (2016) realizaram um estudo para verificar se a caseína hidrolisada teria o 
potencial de minimizar a inflamação decorrente da obesidade e resistência insulínica. Quarenta camundongos machos de 30 dias de vida foram divididos em quatro grupos experimentais: grupo dieta controle e água pura; dieta controle e água com caseína hidrolisada; dieta hiperlipídica e água; dieta hiperlipídica e água com caseína hidrolisada. O tratamento durou 12 semanas e os animais foram eutanasiados. Como resultado, verificaram melhora da tolerância glicêmica nos ratos tratados com dieta hiperlipídica e caseína, diminuição da secreção de citocinas pró-inflamatórias e melhora da sinalização insulínica. A melhora do perfil inflamatório sistêmico poderia indicar menor impacto no metabolismo ósseo de pacientes obesos. Entretanto, neste estudo, não foram observadas diferenças com a utilização da caseína.

Como limitações deste estudo, é possível que o tempo de exposição dos animais à dieta de cafeteria tenha sido insuficiente para que a inflamação advinda da obesidade pudesse influenciar o tecido ósseo mandibular, e os parâmetros sorológicos analisados. O tempo de suplementação de 30 dias com caseína, e o tipo de caseína utilizado (micelar, e não o hidrolisado), podem ter influenciado no resultado. Além disso, o método da gavagem restringiu o contato da caseína com a mucosa gengival, diferente dos estudos citados anteriormente. O tempo de suplementação com caseína, dos 60 aos 90 dias de vida do animal, foi escolhido levando-se em consideração que a partir do $60^{\circ}$ dia o animal é considerado adulto. Optou-se por não avaliar a influência da caseína na infância. Contudo, outros estudos dentro desta temática devem ser conduzidos para o estabelecimento de estratégias preventivas e terapêuticas para o manejo das desordens resultantes da obesidade.

\section{Conclusão}

Nesse estudo, os animais que receberam dieta de cafeteria, com ou sem suplementação com caseína, apresentaram aumento de adiposidade. $\mathrm{O}$ aumento de adiposidade não interferiu nos marcadores plasmáticos (colesterol, triglicerídeos, glicemia, TGO e TGO) e na análise radiográfica da mandíbula desses animais. Histologicamente, os animais com maior adiposidade demonstraram aumento de matriz óssea e diminuição de elementos do tecido ósseo (osteócitos e vasos sanguíneos) do periodonto, entretanto, não foi observado aumento de células inflamatórias. Esses resultados foram independentes da suplementação com caseína. Portanto, a administração de caseína em ratos submetidos a dieta de cafeteria não foi efetiva para diminuir o acúmulo de tecido adiposo, bem como não interferiu positivamente no metabolismo ósseo da mandíbula.

\section{Referências}

Afolabi, H. A., bin Zakariya, Z., Shokri, A. B. A., Hasim, M. N. B. M., Vinayak, R., Afolabi-Owolabi, O. T., Elesho, R. F. (2020). The relationship between obesity and other medical comorbidities. Obes Med, (17), 100164.

Barrett, P., Mercer, J. G., \& Morgan, P. J. (2016). Preclinical models for obesity research. Dis Model Mech, 9 (11), $1245-1255$.

Benayahu, D., Wiesenfeld, Y., Sapir-Koren, R. (2019). How is mechanobiology involved in mesenchymal stem cell differentiation toward the osteoblastic or adipogenic fate? J Cell Physiol, 234 (8), 12133-12141.

Bernardis, L. L. \& Patterson, B. D. (1968). Correlation between 'Lee index' and carcass fat content in weanling and adult female rats with hypothalamic lesions. J Endocrinol, (40), 527-528.

Brin, I., Michaeli, Y., \& Steigman, S. (1990). Long-term Effects of Orthodontic Forces on the Morphology of the Rat-incisor Socket and its Location in the Mandible. J Dent Res, 69 (12), 1834-1838.

Cao, J.J. (2011). Effects of obesity on bone metabolism. J Orthop Surg Res, (6), 30-36.

Chia, J. S. J., McRae, J. L., Enjapoori, A. K., Lefèvre, C. M., Kukuljan, S., \& Dwyer, K. M. (2018). Dietary Cows' Milk Protein A1 Beta-Casein Increases the Incidence of T1D in NOD Mice. Nutrients, $10(9), 1291$.

Coltri, B. M., Costa, K. F. D., Pontillo, V., Bonfleur, M. L., Brancalhão, R. M. C., Beu, C. C. L. et al. (2017). Avaliação morfométrica da influência da obesidade sobre o tecido gengival de ratos com periodontite experimental. Rev Bras Ciênc Saúde, 21 (2), $127-132$.

Compston, J. E., Flahive, J., Hosmer, D. W., Watts, N. B., Siris, E. S., \& Silverman, S. (2014). Relationship of Weight, Height, and Body Mass Index With Fracture Risk at Different Sites in Postmenopausal Women: The Global Longitudinal Study of Osteoporosis in Women (GLOW). J Bone Miner Res, 29 (2), 487-93. 
Compston, J. E., Watts, N. B., Chapurlat, R., Cooper, C., Boonen, S., Greenspan, S., Pfeilschifter, J., Silverman, S., Díez-Pérez, A., Lindsay, R., \& Saag, K. G. (2011). Obesity is not protective against fracture in postmenopausal women: GLOW. Am J Med, 124(11), 1043-50.

Dalmolin, A. C., Rosa, A. R., Grassiolli, S., de Miranda Soares, M. A., \& Omar, N. F. (2018). Mineral Contents and Somatometric Parameters in the Hemimandible, Tibia and Incisor of Rats Submitted to a Hypothalamic Obesity Condition. J Obes Chronic Dis, 2 (2), 57-61.

Didek, D. Cordeiro, M. M., Xavier, J. L. D. P., Ribeiro, P. R., Rentz, T., Franco, G. C. N., et al. (2019). Association Between Exercise and Treatment with Liraglutide in Obese Rats by Cafeteria Diet. Braz Arch. Biol Technol, (62), e19180563.

Duque, G., Ahmed, A. S., Rivas, D., Miard, S., Ferland, G., Picard, F., \& Gaudreau, F. (2020). Differential Effects of Long-Term Caloric Restriction and Dietary Protein Source on Bone and Marrow Fat of the Aging Rat. J Gerontol, 75 (11), 2031-2036.

Eller, L. \& Reimer, R. (2018). Dairy Protein Attenuates Weight Gain in Obese Rats Better Than Whey or Casein Alone. Obesity, (18), 704-711.

Felson, D. T., Zhang, Y., Hannan, M. T., \& Anderson, J. J. (1993). Effects of weight and body mass index on bone mineral density in men and women: The Framingham study. J Bone Miner Res, 8 (5), 567-73.

Fried, A., Manske, S., Eller, L., Lorincz, C., Reimer, R., \& Zernicke, R. (2012). Skim milk powder enhances trabecular bone architecture compared with casein or whey in diet-induced obese rats. Nutrition, (28), 31-335.

Gkastaris, K., Goulis, D. G., Potoupnis, M., Anastasilakis, A. D., \& Kapetanos, G. (2020). Obesity, osteoporosis and bone metabolism. J Musculoskelet Neuronal Interact, 20 (3), 372.

Gomez-Ambrosi, J., Rodriguez, A., Catalan, V., \& Frühbeck, G. (2008). The bone-adipose axis in obesity and weight loss. Obes Surg, 18 (9), $1134-1143$.

Greco, E. A., Fornari, R., Rossi, F., Santiemma, V., Prossomariti, G., Annoscia, C., \& Migliaccio, S. (2010). Is obesity protective for osteoporosis? Evaluation of bone mineral density in individuals with high body mass index. Int J Clin Pract, 64 (6), 817-820.

Hall, W., Millward, D., Long, S., \& Morgan, L. (2003). Casein and whey exert different effects on plasma amino acid profiles, gastrointestinal hormone secretion and appetite. Br J Nut, 89 (2), 239-248.

Healy, N. P., Kirwan, A. M., McArdle, M. A, Holohan, K., Nongonierma, A. B., Keane, D., et al. (2016). A casein hydrolysate protects mice against high fat diet induced hyperglycemia by attenuating NLRP3 inflammasome-mediated inflammation and improving insulin signaling. Mol Nutr Food Res. 60 (11), 24212432 .

Jacobsen, B. B., Leopoldo, A. P. L., Cordeiro, J. P., Campos, D. H. S. D., Nascimento, A. F. D., Sugizaki, M. M., et al. (2017). Cardiac, metabolic and molecular profiles of sedentary rats in the initial moment of obesity. Arq Bras Cardiol, 109 (5), 432-439.

Khojastepour, L., Mohammadzadeh, S., Jazayeri, M., \& Omidi, M. (2017). In vitro Evaluation of the Relationship between Gray Scales in Digital Intraoral Radiographs and Hounsfield Units in CT Scans. J Biomed Phys Eng, 7 (3), 1-10.

Kim, S. P., Frey, J. L., Li, Z., Kushwaha, P., Zoch, M. L., Tomlinson, R. E., \& Riddle, R. C. (2017). Sclerostin influences body composition by regulating catabolic and anabolic metabolism in adipocytes. Proc. Natl. Acad, 114 (52), E11238-E11247.

Kouw, I. W., Holwerda, A. M., Trommelen, J., Kramer, I. F., Bastiaanse, J., Halson, S. L., \& van Loon, L. J. (2017). Protein ingestion before sleep increases overnight muscle protein synthesis rates in healthy older men: a randomized controlled trial. J Nutr, 147 (12), 2252-2261.

Lillefosse, H. H., Tastesen, H. S., Du, Z. Y., Ditlev, D. B., Thorsen, F. A., Madsen, L., \& Liaset, B. (2013). Hydrolyzed casein reduces diet-induced obesity in male C57BL/6J mice. J Nutr, 143 (9), 1367-1375.

Marine-Casado, R., C. Domenech-Coca, C., Del Bas, J. M., Bladé, C., Arola, L., \& Caimari, A. (2018). Intake of an Obesogenic Cafeteria Diet Affects Body Weight, Feeding Behavior, and Glucose and Lipid Metabolism in a Photoperiod-Dependent Manner in F344 Rats. Front Physiol, (9), 1639.

Messer, J. G., Jiron, J. M., Chen, H. Y., Castillo, E. J., Mendieta Calle, J. L., Reinhard, M. K., et al. (2017). Prevalence of food impaction-induced periodontitis in conventionally housed marsh rice rats (Oryzomys palustris). Comparative Med, 67 (1), 43-50.

Messer, J. G., La, S., Kipp, D. E., Castillo, E. J., Yarrow, J. F., Jorgensen, M., et al. (2019). Diet-induced Generalized Periodontitis in Lewis Rats. Comparative Med, 69 (5), 384-400.

Mirzababaei, A., Mirzaei, K., Khorrami-Nezhad, L., Maghbooli, Z., \& Keshavarz, S. A. (2017). Metabolically healthy/unhealthy components may modify bone mineral density in obese people. Arch Osteoporos, 12 (1), 1-9.

Mundim, M. B. V., Dias, D. R., Costa, R. M., Leles, C. R., Azevedo-Marques, P. M., \& Ribeiro Rotta R. F. (2016). Intraoral radiographs texture analysis for dental implant planning. Comput Methods Programs Biomed, (36), 89-96.

Nahin, R. L., Barnes, P. M., Stussman, B. J., \& Bloom, B. (2009). Costs of complementary and alternative medicine (CAM) and frequency of visits to CAM practitioners: United States, 2007. Natl Health Stat Report, 30 (18), 1-14.

Proietto J. (2020). Obesity and Bone. F1000Res, 9 (1), 1-7.

Ramos-Junior, E. S., Leite, G. A., Carmo-Silva, C. C., Taira, T. M., \& Neves, K. B. (2017). Adipokine chemerin bridges metabolic dyslipidemia and alveolar bone loss in mice. J Bone Miner Res, 32 (5), 974-984.

Rauch, A., Haakonsson, A. K., Madsen, J. G. S., \& Mandrup, S. (2019). Osteogenesis depends on commissioning of a network of stem cell transcription factors that act as repressors of adipogenesis. Nat Genet, (51), 716-727.

Rowe, P., Koller, A., \& Sharma, S. (2020). Physiology, bone remodeling. Treasure Island (FL): StatPearls Publishing. 
Research, Society and Development, v. 10, n. 7, e1410716169, 2021

(CC BY 4.0) | ISSN 2525-3409 | DOI: http://dx.doi.org/10.33448/rsd-v10i7.16169

Sawin, E., Stroup, B., Murali, S., O'Neill, L., Ntambi, J., \& Ney, D. (2016). Differential Effects of Dietary Fat Content and Protein Source on Bone Phenotype and Fatty Acid Oxidation in Female C57B1/6 Mice. PLOS ONE, 32-33.

Schetz, M., De Jong, A., Deane, A. M., Druml, W., Hemelaar, P., Pelosi, P., Pickkers, P., Reintam-Blaser, A., Roberts, J., Sakr, Y., \& Jaber, S. (2019). Obesity in the critically ill: a narrative review. Intensive Care Med, 45 (6), 757-769.

Schoemaker, M. H., Kleemann, R., Morrison, M. C., Verheij, J., Salic, K., van Tol, E. A., et al. (2017). A casein hydrolysate based formulation attenuates obesity and associated non-alcoholic fatty liver disease and atherosclerosis in LDLr-/-.Leiden mice. PLoS One, 12 (7), e0180648, 2017.

So, I., \& Yadav, H. (2020). Obesity and Its Complications Pathogenesis. In: Pathophysiology of Obesity-Induced Health Complications. Springer, Cham, (19), 43-56.

Tappia, P. S., \& Defried, D. (2020). Prevalence, Consequences, Causes and Management of Obesity. In: Pathophysiology of Obesity-Induced Health Complications. Springer, Cham, (19), 3-22.

Walsh, J. S., \& Vilaça, T. (2017). Obesity, Type 2 Diabetes and Bone in Adults. Calcif Tissue Int, (100), 528-35.

Wong, S. K., Chin, K. Y., Suhaimi, F. H., Ahmad, F., \& Ima-Nirwana, S. (2018). Effects of metabolic syndrome on bone mineral density, histomorphometry and remodelling markers in male rats. PLoS One, 13(2), e0192416.

Zhou, M., Li, S., \& Pathak, J. L. (2019). Pro-inflammatory Cytokines and Osteocytes. Curr Osteoporos, (17), 97-104. 